\title{
Near infrared fluorescent imaging of choline kinase alpha expression and inhibition in breast tumors
}

\author{
Sean P. Arlauckas¹, Manoj Kumar ${ }^{1}$, Anatoliy V. Popov ${ }^{1}$, Harish Poptani², ${ }^{1}$, Edward \\ J. Delikatny ${ }^{1}$ \\ ${ }^{1}$ Department of Radiology, Perelman School of Medicine, University of Pennsylvania, Philadelphia, PA, United States \\ ${ }^{2}$ Department of Cellular and Molecular Physiology, Institute of Regenerative Medicine, University of Liverpool, Liverpool, United Kingdom
}

Correspondence to: Edward J. Delikatny, email: delikatn@mail.med.upenn.edu

Keywords: choline kinase, breast cancer, fluorescence optical imaging, chemotherapy

Received: November 18, 2016

Accepted: January 16, 2017

Published: February 01, 2017

\section{ABSTRACT}

Choline kinase alpha (ChoKa) overexpression is associated with an aggressive tumor phenotype. ChoKa inhibitors induce apoptosis in tumors, however validation of their specificity is difficult in vivo. We report the use of optical imaging to assess ChoKa status in cells and in vivo using JAS239, a carbocyanine-based ChoKa inhibitor with inherent near infrared fluorescence. JAS239 attenuated choline phosphorylation and viability in a panel of human breast cancer cell lines. Antibody blockade prevented cellular retention of JAS239 indicating direct interaction with ChoKa independent of the choline transporters and catabolic choline pathways. In mice bearing orthotopic MCF7 breast xenografts, optical imaging with JAS239 distinguished tumors overexpressing ChoKa from their empty vector counterparts and delineated tumor margins. Pharmacological inhibition of ChoK by the established inhibitor MN58b led to a growth inhibition in 4175 -Luc+ tumors that was accompanied by concomitant reduction in JAS239 uptake and decreased total choline metabolite levels as measured using magnetic resonance spectroscopy. At higher therapeutic doses, JAS239 was as effective as MN58b at arresting tumor growth and inducing apoptosis in MDA-MB-231 tumors, significantly reducing tumor choline below baseline levels without observable systemic toxicity. These data introduce a new method to monitor therapeutically effective inhibitors of choline metabolism in breast cancer using a small molecule companion diagnostic.

\section{INTRODUCTION}

Choline kinase alpha $(\mathrm{ChoK} \alpha)$ has become the subject of intense interest for its utility as an oncogenic biomarker as well as an anticancer therapeutic target [1-5]. ChoK $\alpha$ catalyzes choline phosphorylation as an intermediate step in the synthesis of two abundant membrane phospholipids, phosphatidylcholine (PtdCho) and sphingomyelin. Elevated ChoKa activity has been identified in approximately $40 \%$ of human breast tumors [6], and aberrant choline metabolism has been reported in lung, breast, colorectal, prostate, brain, bladder, and pancreatic cancers [7-10]. ChoK $\alpha$ produces phosphocholine (PC), which is critical for cell growth and for the regulation of cell proliferation by growth factors [11]. During malignant transformation, cells sequester high levels of $\mathrm{PC}$ that are detectable using ${ }^{1} \mathrm{H}$ magnetic resonance spectroscopy (MRS) due to the nine chemically-equivalent protons on the methyl groups of the quaternary nitrogen $[12,13]$. ChoK $\alpha$ can be activated by the Ras and RhoA oncogenes, although overexpression of ChoK $\alpha$ alone is sufficient to transform cells to a malignant phenotype [14-16].

ChoK $\alpha$ inhibitors have been developed to study the involvement of this enzyme in malignant transformation. Shutting down de novo phospholipid biosynthesis leads to lower levels of pro-mitotic second messenger Kennedy pathway intermediates, increased ceramide levels, and de-stabilized endoplasmic reticulum [2, 17-19]. The most potent of these agents, TCD-717, is a promising anticancer drug [19] that is being evaluated in clinical trials [20]. MN58b, a bis-cationic ChoK $\alpha$ inhibitor, has been demonstrated to be lethal to lymphoma cells, but causes a reversible cell cycle arrest in normal cells [17]. Although 
the mechanism by which ChoK $\alpha$ inhibition causes cell death may involve scaffolding in addition to enzymatic functions [21], measurement of total choline-containing metabolite (tCho) levels by MRS is still the primary method of validating ChoK inhibitors in vivo [22, 23]. A limitation of this approach is that metabolite levels are also affected by the contributions of phospholipases, organic cation transporters, and sphingomyelinases [3, 24, 25]. Moreover, cell death can lead to deceptive decreases in tCho in MR spectra, requiring the measurement of secondary biomarkers $[26,27] .{ }^{18} \mathrm{~F}$ and ${ }^{11} \mathrm{C}$ choline PET tracers are useful for identifying ChoK inhibition [28], but choline tracer accumulation can be affected by choline transport inhibitors [29, 30] which have known toxicities [31]. In addition, recent reports have shown that ChoK $\alpha$ protein scaffolding, rather than the enzymatic function, may be critical for supporting cell viability [21, 32, 33]. Miyake and Parsons reported a c-Src-dependent link between ChoK $\alpha$ and EGFR [32]. More recent studies showed that small molecule non- symmetric ChoK $\alpha$ inhibitors with low $\mathrm{nM} \mathrm{IC}_{50} \mathrm{~s}$ could substantially reduce the metabolic product PC but only cause reversible growth arrest with no effects on cell viability [21, 33]. Thus further development of fluorescence-based imaging strategies that report on enzyme expression rather than enzyme activity is needed.

We have recently reported fluorescent small molecule choline mimetics (JAS239) that effectively attenuate choline phosphorylation. The structural similarity between symmetric, bis-heterocyclic ChoK $\alpha$ inhibitors and a class of carbocyanine dyes used for optical imaging led to the development of these enzyme inhibitors with near infrared fluorescence (NIRF) [4]. Within this wavelength range human tissue is relatively transparent [34-36] and NIRF optical imaging probes can be detected through several millimeters, and up to centimeters of tissue $[37,38]$. Moreover, these probes exhibit a concentration dependent cellular uptake that cannot be attenuated in the presence of excess free choline indicating that they enter the cell independently of the choline transporters [4]. There is a particular need for more specific agents to assist surgeons in distinguishing tumor from normal tissue [36, 39], and intraoperative imaging is an expanding field for which NIRF offers an inexpensive and effective method of delineating tumor margin and assessing lymph node involvement [40-42]. In this work we investigate JAS239 as a NIRF ChoK $\alpha$ targeted optical imaging probe in murine orthotopic breast tumors and compare this diagnostic method to MRS. In vitro, JAS239 was validated against MN58b and shown to have comparable potency to block cell growth and inhibit choline phosphorylation in breast cancer cell lines. In vivo, we demonstrate that JAS239 can be used to distinguish overexpression of ChoK $\alpha$ in breast tumor models and monitor ChoK $\alpha$ inhibition induced by MN58b. At higher doses, JAS239 was compared to MN58b to assess the therapeutic potential of ChoK $\alpha$ inhibitors in these tumor models. A therapeutic course of JAS239 was able to significantly reduce tumor tCho levels, reduce tumor cell density, decrease proliferation, and cause apoptosis and tumor growth arrest.

\section{RESULTS}

\section{Characterization of inhibitor sensitivity in a breast cancer cell line panel}

Inhibition of ChoK $\alpha$ by JAS239 and MN58b was measured in 4 breast cancer cell lines, MCF7 overexpressing ChoK (MCF7-CK+) [43], the corresponding empty vector cell line (MCF7-EV), MDAMB-231, and 4175-Luc+, an MDA-MB-231 derivative harvested from a lung metastasis and transfected with luciferase [44]. The MCF7-CK+ line was confirmed to have elevated $\mathrm{ChoK} \alpha$ expression and activity relative to MCF7-EV cells (Supporting Information, Supplementary Figure 1A-1B) [4]. No significant difference in ChoK $\alpha$ expression or activity was observed between the triple-negative MDA-MB-231 and 4175-Luc+ lines (Supplementary Figure 1A-1B). MN58b attenuated the elevated ChoK $\alpha$ activity in MCF7-CK + cells with similar efficacy to the control MCF7-EV cell line as indicated by the $\mathrm{IC}_{50}$ (Table 1, Supplementary Figure 1C). Similarly, no significant difference in $\mathrm{IC}_{50}$ was found between the MDA-MB-231 and the 4175-Luc+ cell lines after $2 \mathrm{~h}$ of MN58b treatment (Table 1, Supplementary Figure 1D). MN58b was at least twice as effective as JAS239 at reducing choline phosphorylation at $2 \mathrm{~h}$ in all cell lines tested (Table 1, Supplementary Figure 1C-1F).

Extended treatment of cancer cells with $\mathrm{ChoK}$ inhibitors leads to cell death by apoptosis [19]. After $17 \mathrm{~h}$, we found no significant difference in the $\mathrm{EC}_{50} \mathrm{~S}$ between MN58b (Table 1, Supplementary Figure 2A) and JAS239 in the MCF-7 EV and CK+ cell lines (Table 1, Supplementary Figure 2B) by Trypan blue exclusion. As was found in radiotracing assays, MN58b was more potent at inhibiting cell growth than JAS239 in MDA-MB-231 and 4175-Luc+ cells although the results were more variable (Table 1, Supplementary Figure 2C-2D).

\section{JAS239 colocalization with ChoKa}

Fluorescence confocal micrographs of fixed MDAMB-231 cells treated with an anti-human $\mathrm{ChoK} \alpha$ antibody are shown in Figure 1, top. When treated individually, no overlap was observed between the Texas-Red (ChoK $\alpha$ antibody) and JAS239 channels (see also Supplementary Figure 3A). MDA-MB-231 cells stained with JAS239 and probed with the $\mathrm{ChoK} \alpha$ antibody revealed strong colocalization (Figure 1, middle and Supplementary Figure 3A). Of the ChoK $\alpha$-positive pixels, $89+9 \%$ were also positive for JAS239 (Supplementary Figure 3B). 
Table 1: Potency of MN58b and JAS239 in a panel of breast cancer cell lines

\begin{tabular}{lcccc}
\hline & \multicolumn{2}{c}{$\mathbf{I C}_{\mathbf{5 0}}(\boldsymbol{\mu M})$} & \multicolumn{2}{c}{$\mathbf{E C}_{\mathbf{5 0}}(\boldsymbol{\mu M})$} \\
\hline \multicolumn{1}{c}{ Cell Line } & MN58b & JAS239 & $3.29 \pm 0.48$ & $4.04 \pm 0.55$ \\
\hline MCF7-EV & $3.85 \pm 0.42$ & $11.1 \pm 5.64$ & $6.86 \pm 0.43$ & $5.33 \pm 0.84$ \\
MCF7-CK+ & $2.36 \pm 0.28$ & $10.3 \pm 2.48$ & $14.26 \pm 4.6$ & $27.2 \pm 7.9$ \\
MDA-MB-231 & $4.36 \pm 1.37$ & $9.92 \pm 0.22$ & $20.7 \pm 6.4$ & $35.0 \pm 21.6$ \\
4175-Luc + & $4.59 \pm 0.55$ & $9.89 \pm 0.24$ & JAS239 \\
\hline
\end{tabular}

Cells were treated with varying concentrations of MN58b or JAS239 and analyzed after $2 \mathrm{~h}$ for ${ }^{14} \mathrm{C}-\mathrm{PC}$ production or after $17 \mathrm{~h}$ for cell viability. Data for 3 separate experiments were fitted to sigmoidal plots and $\mathrm{IC}_{50} \mathrm{~s}$ and $\mathrm{EC}_{50} \mathrm{~s}$ are reported $\pm \mathrm{SEM}$ for the radiotracing and viability assays, respectively.

Similarly, $89+10 \%$ of JAS239-positive pixels were positive for ChoK $\alpha$ (Supplementary Figure 3C). When cells were pre-treated with ChoK $\alpha$ antibody, marked reduction in JAS239 retention was detected (Figure 1, bottom). Reduced JAS239 signal caused a lower Pearson's Correlation Coefficient, although $84+4 \%$ of the regions which were ChoK $\alpha$-positive were also JAS239-positive (see Supplementary Figure 3B), and 87 $+2 \%$ of the JAS239-positive pixels were ChoK $\alpha$-positive (see Supplementary Figure 3C). This demonstrates that JAS239 retained in these cells was still associated with
ChoK $\alpha$, even though the intensities followed a different distribution trend. These results are consistent with JAS239 being out-competed by the antibody for binding sites.

\section{NIRF imaging facilitates study of JAS239 biodistribution}

Tumors derived from 4175-Luc+ cell lines had the most rapid in vivo growth (see Supplementary Figure 4A-4B) that could additionally be monitored

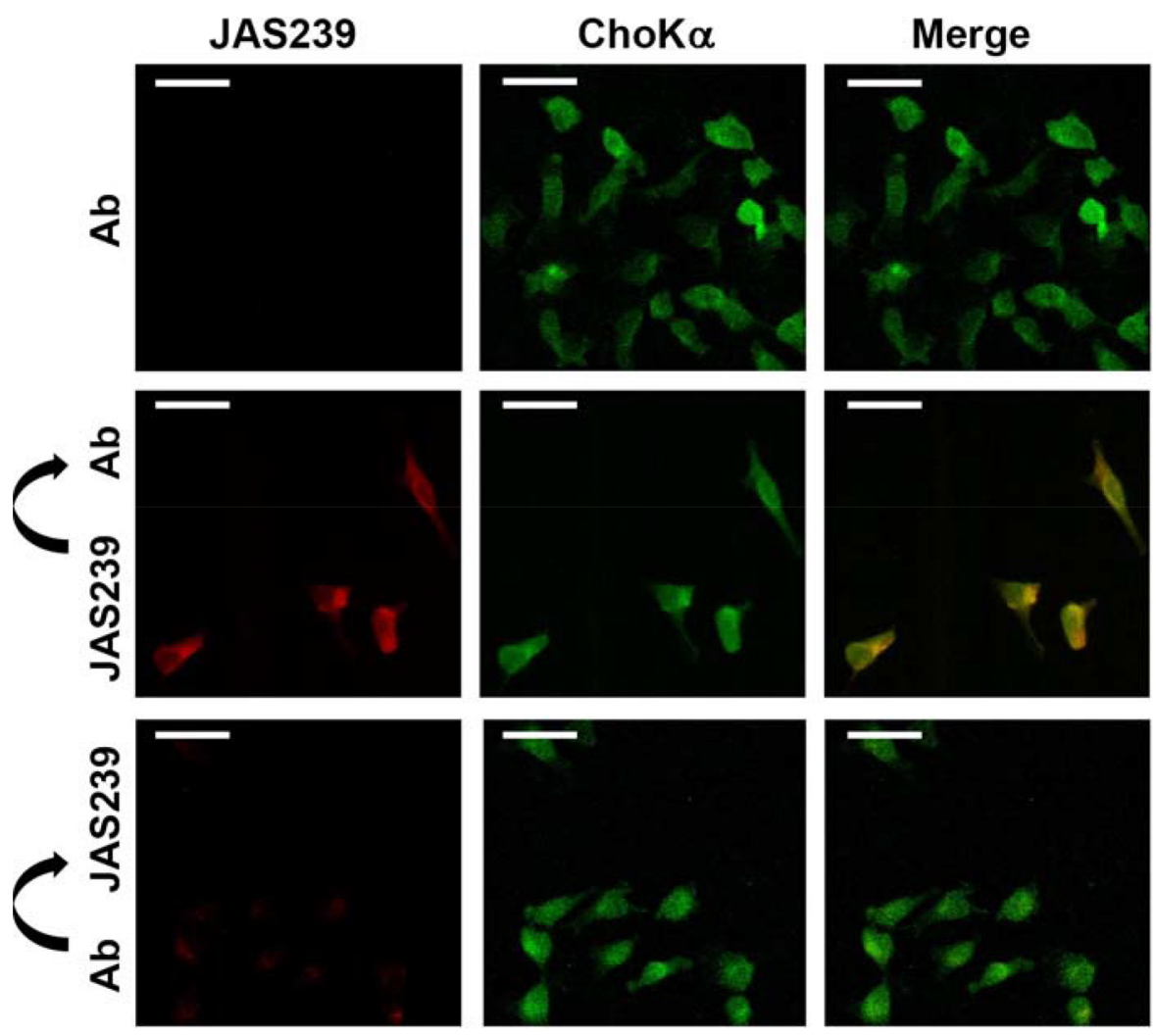

Figure 1: JAS239 colocalizes with ChoK $\boldsymbol{\alpha}$. Fixed permeabilized MDA-MB-231 cells treated with a ChoK $\alpha$-specific antibody (Ab) followed by a Texas Red-conjugated secondary antibody (Ex. $543 \mathrm{~nm}$; Em. 565-615 nm) were assessed by confocal microscopy (top row). In cells stained with JAS239 followed by the ChoK $\alpha$ antibody (middle row), strong colocalization between the JAS239 (Ex. $633 \mathrm{~nm}$; Em. $>650 \mathrm{~nm}$ ) and ChoK $\alpha$ is observed. Cells incubated with ChoK $\alpha$ antibody prior to JAS239 staining (bottom row) no longer retain the NIRF probe. Scale bar represents $35 \mu \mathrm{m}$. 
with bioluminescence imaging. Bioluminescence in mice bearing orthotopic 4175-Luc+ tumors was measured 15 min following luciferin injection (Supplementary Figure 5A). This signal was used to delineate the tumor margins (in blue) and was used to confirm that the bioluminescence did not overlap with the NIR range (Supplementary Figure 5B). The next day no residual luminescence was detected, and mice were treated with control vehicle (Figure 2A, left mouse) or $20 \mathrm{nmol} \mathrm{JAS} 239$ in Tween-80/Tris buffer (Figure 2A, right mouse). After initial hepatic clearance (approximately $75 \mathrm{~min}$ ), mice were injected i.p. with luciferin and imaged for bioluminescence and NIRF 15 min later. Bioluminescence was again used to delineate the tumor margin (Supplementary Figure 5C), and no NIRF signal was detected in the control animals (Figure 2A, left mouse; $n=5$ ). In the JAS239-injected animals, NIRF was emitted both from the tumor and from the kidneys (Figure $2 \mathrm{~A}$, right mouse; $n=4$ ). NIRF emission at $800 \mathrm{~nm}$ was an order of magnitude stronger in JAS239-injected animals vs. control (Figure 2B). The maximum NIRF contrast between the tumor and background was achieved 90 minutes post-JAS239 injection, tumor fluorescence diminished after this time due to excretion (Supplementary Figure 5D).

Mice from this cohort were injected one week later (allowing the first dose to clear entirely) with JAS239, euthanized $90 \mathrm{~min}$ later, and the organs resected and imaged (Figure 2C). The biodistribution of JAS239 is consistent with the renal signal detected in whole animals, however the signal from other organs (liver in particular) was higher than would be expected from whole-body images (Figure 2D). The tumor contrast seen in wholebody NIRF images is enhanced due to the relative depth of these organs, compared to the surface tumor.

A cohort of 5 mice was inoculated with subcutaneous 4175-Luc+ tumors high on the right flank. This cohort was injected with JAS239 in an ethanol/saline vehicle. Fluorescence from the kidneys was the dominant source of NIRF signal (Figure 2E). Intentional placement of these tumors on the shoulders allowed us to cloak the lower extremities and isolate the tumor for NIRF imaging (Figure 2F). Tumor signal to noise was highest at $24 \mathrm{~h}$ and the organs in these animals were resected and imaged to estimate biodistribution (Figure $2 \mathrm{G}$ ). Compared to the Tween-80/Tris vehicle, hepatic signal from JAS239 in this formulation dropped nearly one order of magnitude, drastically reducing background signal (Figure $2 \mathrm{H}$ ). At this time, a nearly two-fold tumor-to-muscle ratio was found ex vivo (Figure 2I).

\section{Optical imaging of JAS239 to assess ChoKa status}

The effect of genetic overexpression of ChoK $\alpha$ on JAS239 retention was studied in mice bearing orthotopic MCF7-EV and MCF7-CK+ tumors (Figure 3A) that were injected with JAS239 in ethanol/saline vehicle.
Optical imaging of the surgically exposed mammary fat pads revealed distinct NIRF signal within the confines of the orthotopic tumor, and tumor margins could clearly be delineated (Figure 3B). JAS239 accumulation was significantly higher in MCF7-CK+ tumors compared to contralateral MCF7-EV tumors (Figure 3C). A significant but more moderate increase in NIRF was observed between exposed MCF7-EV and MCF7-CK+ fat pad tumors in mice injected with JAS239 in Tween-80/Tris buffer 90 min prior (see Supplementary Figure 5E).

MN58b treatment was used to model pharmacologic inhibition of ChoK $\alpha$. Mice bearing orthotopic 4175-Luc+ tumors were imaged with in vivo MRS and then treated with a 5-day dose regimen of MN58b at $2 \mathrm{mg} / \mathrm{kg} /$ day i.p. In vivo MRS 7 days later (Figure 3D-3E) showed reduced tCho levels after MN58b treatment (Figure 3E-3F). In control-treated animals tCho levels increased substantially during the one-week period (Figure 3F). These animals underwent post-treatment JAS239 injections with followup NIRF imaging (Figure 3G), and MN58b treatment reduced intratumoral JAS239 accumulation relative to untreated tumors (Figure $3 \mathrm{H}$ ).

\section{JAS239 is a therapeutically effective ChoKa inhibitor in breast xenograft models}

To test the therapeutic potential of JAS239, a group of athymic nude mice with 4175-Luc+ tumors were given a 5-day i.p. dose treatment regimen of JAS239 or MN58b beginning 3 days after orthotopic tumor inoculation. Both $2 \mathrm{mg} / \mathrm{kg} /$ day MN58b-treatment and $4 \mathrm{mg} / \mathrm{kg} /$ day JAS239treatment resulted in significantly smaller tumor volumes compared to control animals (Figure 4A). Until day 26, both the MN58b and JAS239 cohorts had significantly smaller ( $P=0.021$ and 0.022 , respectively) tumors than the vehicle-treated group.

To study the metabolic effects of JAS239 therapy on tumors, tCho was used as a pharmacodynamic marker of ChoK $\alpha$ inhibition (Figure 4B). MDA-MB-231 xenografts were used because prior characterization of MN58b in this model [22] allowed for the confident use of this inhibitor as a positive control. MRI volume measurements indicated that vehicle-treated tumors grew during the week between pre- and post-treatment MRS scans (Paired $t$-test: $P=0.009$ ), whereas MN58b-treated and JAS239-treated tumors were static during the same time span (Supplementary Figure 6A). Single voxel MRS in each tumor (Supplementary Figure 6B-6D), showed that tCho increased during the time course in controls (Figure 4B-4C). Significant reductions in tCho compared to control were observed in response to $\mathrm{MN58b}$ $(P=0.006$, Figure 4B, 4D) and JAS239 $(P=0.004$, Figure 4B, 4E). JAS239 treatment was able to reduce tCho to noise levels in these tumors. Polyunsaturated fatty acid (PUFA) resonances, a measure of tumor apoptosis [45], increased after MN58b and JAS239 treatment, although 
this trend was not significant (Supplementary Figure 6E). Supplementary Figure $6 \mathrm{~F}$ depicts a summary of the toxicology of the mice from this experiment, revealing no significant effects except for elevation of blood urea nitrogen in MN58b-treated animals compared to controls $(P=0.012)$.

Tumors from MDA-MB-231-bearing mice were harvested for histological assessment immediately after follow-up MRI/MRS scanning (Figure 5A). Evaluation of H\&E slides (Figure 5B) showed that both MN58b $(P=0.007)$ and JAS239 $(P=0.01)$ caused significant reduction in cell density. MN58b $(P=0.026)$ and JAS239
$(P=0.034)$ treatment significantly reduced the percentage of Ki67-positive cells compared to the control group (Figure 5C). Consistent with reduced cell number and proliferation, higher caspase-3 levels (Figure 5D) were detected in MN58b $(P=0.016)$ and JAS239 $(P=0.015)$ treated tumors than in controls.

\section{DISCUSSION}

JAS239 is a ChoK $\alpha$ inhibitor whose inherent near infrared fluorescence makes it possible to measure its interaction with cancer cells. In this study, we investigated
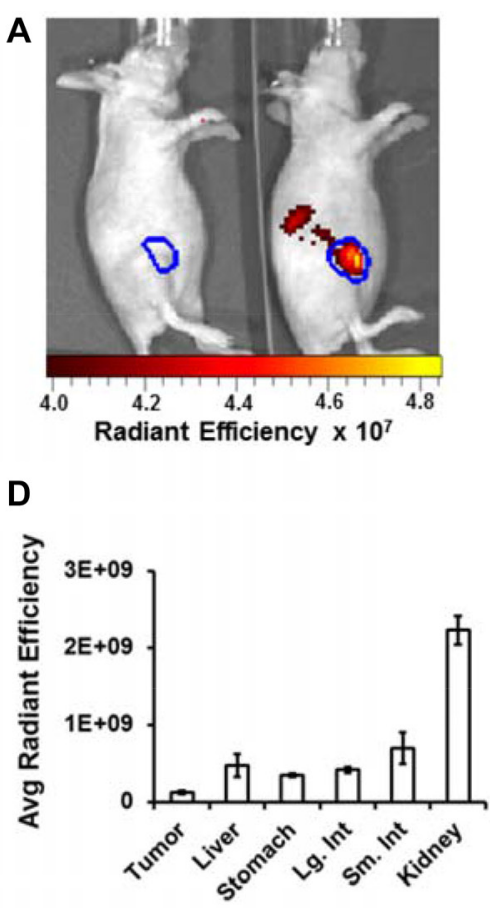

G

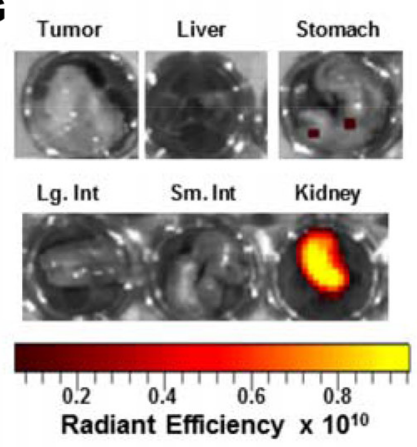

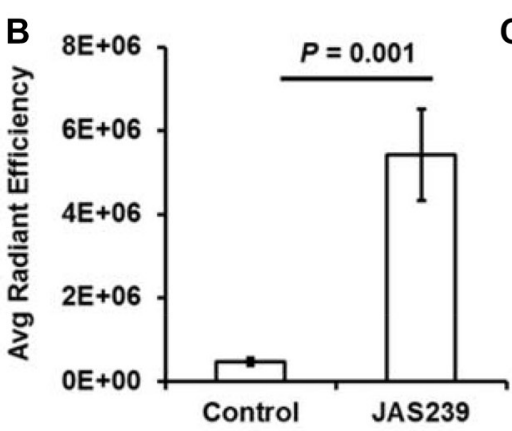

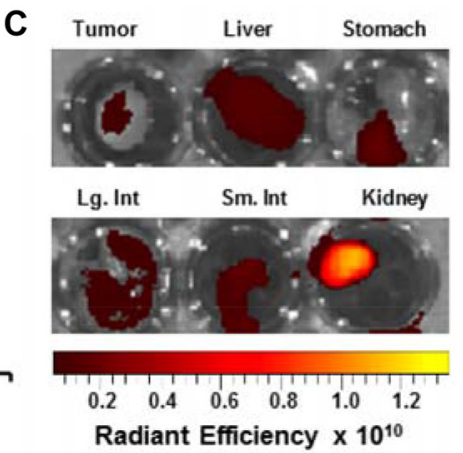

E

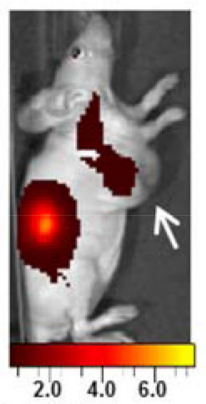

Radiant Efficiency $\times 10^{9}$

$\mathbf{F}$

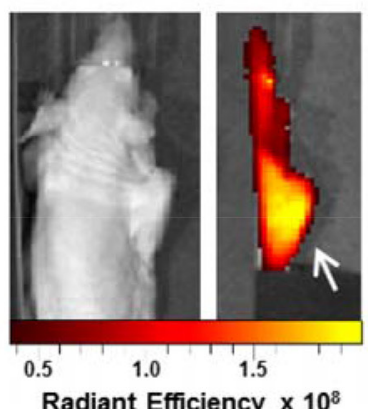

H

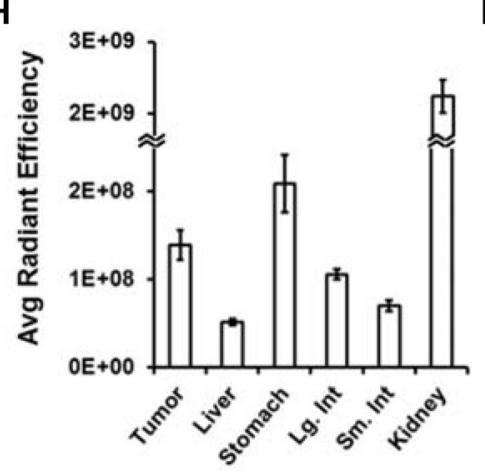

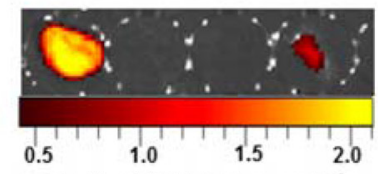

तadiant Efficiency $\times 10^{8}$

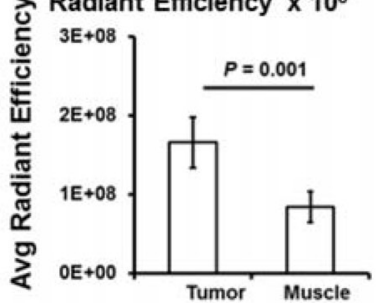

Figure 2: In vivo optical imaging provides JAS239 biodistribution data. (A) Tumor margin (blue) defined by bioluminescent imaging of 4175-Luc+ tumors shows no NIRF in vehicle-injected mouse (left) but intratumoral NIRF in right mouse injected with JAS239 in Tween-80/Tris Buffer. Renal excretion of JAS239 is also seen outside the tumor boundaries. (B) Quantified Average Radiant Efficiency $\left[\mathrm{p} / \mathrm{sec} / \mathrm{cm}^{2} / \mathrm{sr}\right] /\left[\mu \mathrm{W} / \mathrm{cm}^{2}\right]$ in tumor ROIs $(n=4)$. $(\mathbf{C}, \mathbf{D})$ Organs resected $90 \mathrm{~min}$ following JAS239 injection imaged for NIRF (C) and quantified for comparison. (E) Delivered in an ethanol/saline formulation, maximal intratumoral JAS239 (white arrow) relative to background was achieved $24 \mathrm{~h}$ post-injection. (E, F) Tumors (white arrow) moved to shoulder allow organs involved in JAS239 excretion to be cloaked. (G, H) Resected organs 24 h post-injection of JAS239 imaged for NIRF (G) and quantified (H). (I) Tumor and muscle NIRF were quantified and were found to be significantly different. Unless otherwise noted, cohort size was 5 animals and values represent \pm SEM. Total JAS239 delivered was $20 \mathrm{nmol} /$ animal. 
the ability of JAS239 to detect ChoK $\alpha$ expression in human xenograft models of breast cancer. We first verified the response to ChoK $\alpha$ inhibition by JAS239 in a panel of human breast cancer cells representing different germ lines (epithelial and mesenchymal), tumor stages (estrogen-positive and triple-negative), derivation (mousenaïve and mouse-adapted), and ChoK $\alpha$ expression (low and high). Using confocal microscopy, JAS239 staining was compared with ChoK $\alpha$ expression measured using immunohistochemistry. Colocalization of the probe with ChoK $\alpha$ was observed, indicating a direct interaction that could be blocked when the N-terminal antibody was applied first. This is consistent with a mechanism of competitive inhibition of the active site of ChoK $\alpha$ [4].

Against pure yeast $\mathrm{ChoK} \alpha$, the average reported $\mathrm{IC}_{50} \mathrm{~s}$ of the bis-pyridinium and bis- quinolinium ChoK $\alpha$ inhibitors are 37.1 and $33.9 \mu \mathrm{M}$, respectively; the antiproliferative activities, $\mathrm{EC}_{50} \mathrm{~s}$, in HT-29 cells are 19.7 and $3.7 \mu \mathrm{M}$, respectively [46-47]. Although determined in different systems, the measured $\mathrm{IC}_{50}$ of $4.6 \mu \mathrm{M}$ for JAS239 represents potency comparable to or better than $85 \%$ of the reported bis-pyridinium-based $\mathrm{ChoK} \alpha$ inhibitors, and
$61 \%$ of the bis-quinolinium compounds. The $\mathrm{EC}_{50}$ values are also comparable, although determined using different assays in cell lines of different tissue origin. The action of JAS239 against MDA-MB-231 cells suggests ChoK $\alpha$ inhibition may be an effective strategy in triple- negative breast cancers, which are often therapy resistant. Its potency suggests that further modifications based upon the carbocyanine template, and subsequent structure-activity characterization, may yield compounds with higher specificity to ChoK $\alpha$.

While in vitro data can often be promising, translation to in vivo models is crucial for a true assessment of the efficacy and feasibility of this technology. In vivo biodistribution showed that JAS239, a cationic small molecule, accumulated and was cleared through the kidneys. An initial flush was observed in the liver where ChoK $\alpha$ is naturally abundant [48], but this is also the site of first-pass metabolism. With the guidance of bioluminescence imaging in 4175-Luc+ tumor xenografts, intratumoral JAS239 NIRF was detectable but eventually drowned out by renal filtration and excretion of the probe. This result does not disparage the translational utility
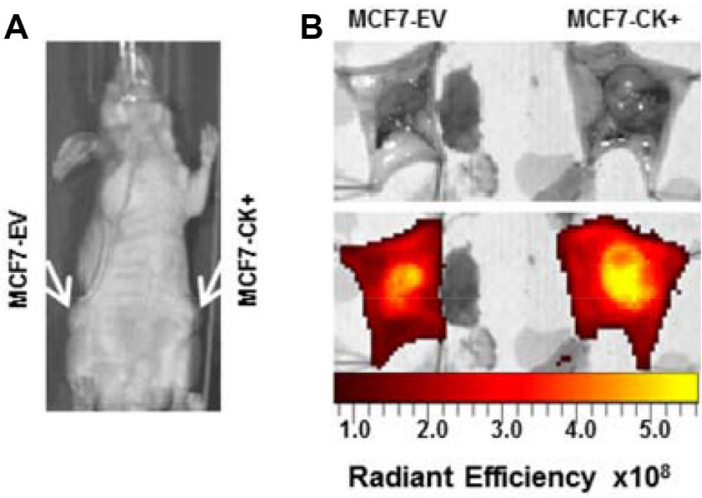

E

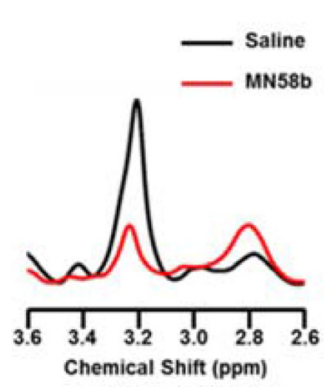

$\mathbf{F}$

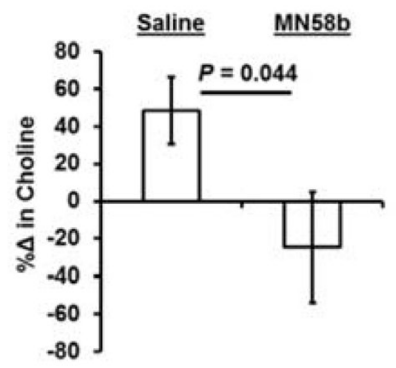

\section{C}
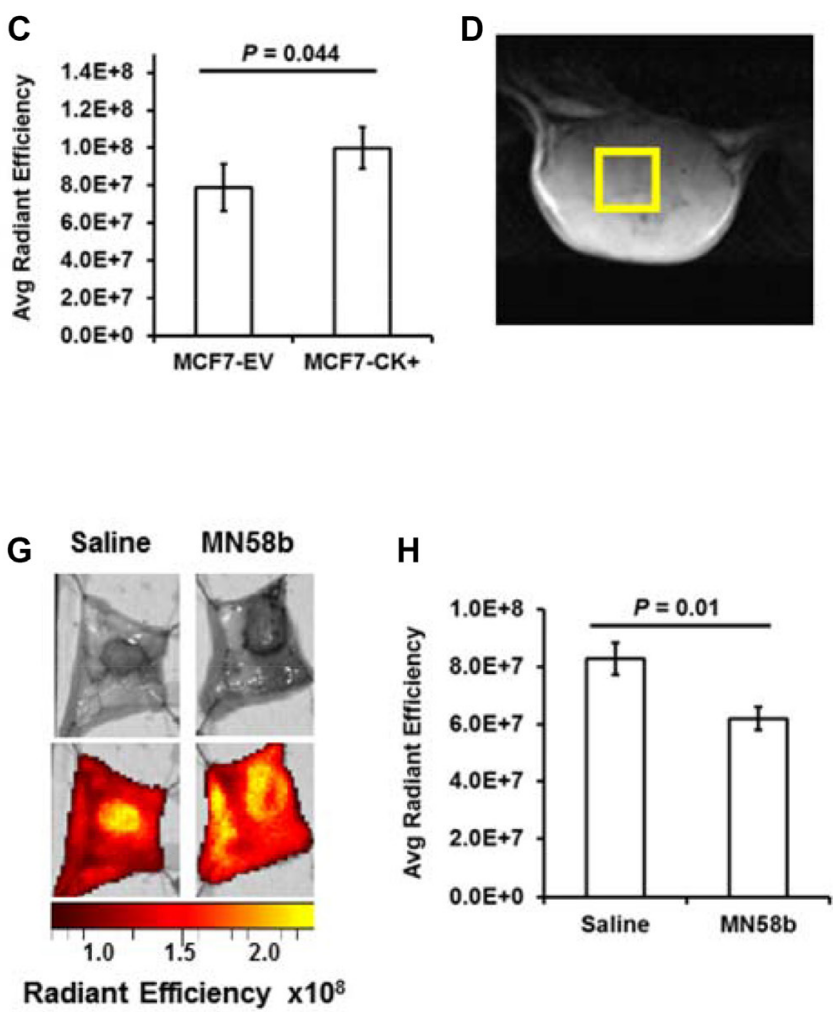

Figure 3: NIRF imaging for JAS239 accumulation can detect genetic overexpression and pharmacologic inhibition of ChoKo. (A) Athymic nude mice were inoculated with MCF7-EV (left mammary fat pad) and MCF7-CK+ (right mammary fat pad) cells. (B) Tumor-bearing fat pads were surgically exposed and imaged for NIRF $24 \mathrm{~h}$ after JAS239 injection in an ethanol formulation. (C) Quantified Average Radiant Efficiency $\left[\mathrm{p} / \mathrm{sec} / \mathrm{cm}^{2} / \mathrm{sr}\right] /\left[\mu \mathrm{W} / \mathrm{cm}^{2}\right]$ of resected fat pads reveals enhanced JAS239 retention in ChoK $\alpha$ overexpressing tumors $(n=7)$. (D) Representative $T_{2}$-weighted MR image of a 4175 -Luc + tumor used to plan $3 \times 3 \times 3 \mathrm{~mm}^{3}$ voxel placement. (E) In vivo MR spectra of the choline (3.2 ppm) and PUFA $(2.8 \mathrm{ppm})$ regions for control (black) and MN58b-treated (red) tumors. (F) MN58b-treatment prevents the increase in intratumoral tCho (3.2 ppm) observed between scans in the control cohort. (G, H) NIRF of the exposed saline (left) or MN58b-treated (right) tumors (G) was quantified and MN58b-induced ChoK $\alpha$ inhibition diminishes JAS239 retention significantly $(\mathrm{H})$. For saline and MN58b groups, $n=5$. Values are reported as $\pm \mathrm{SEM}$. 
of this probe, as clinical optical imaging is not a wholebody but rather a tissue or region-specific measurement, especially when employed in an intraoperative setting [39].

While biodistribution studies showed that JAS239 could be detected in other major organs, the tumor/muscle ratio suggests that measurements confined to the breast region were robust enough to distinguish malignant from normal tissue. This was further verified when tumorbearing mammary fat pads of JAS239-injected mice were surgically exposed and imaged with NIRF optical imaging. JAS239 accumulation was found to be a reliable identifier of ChoK $\alpha$ overexpressing tumors in matched MCF7-EV and CK+ tumors. Although the difference in JAS239 fluorescence between $\mathrm{EV}$ and $\mathrm{CK}+$ tumors was moderate, the observed tumor/normal tissue fluorescence ratio of $2.8 \pm 0.2$ was sufficient to distinguish malignant from normal tissue and is similar to values reported for other agents currently being used for fluorescence-guided tumor resection [42]. To assess the validity of this imaging strategy we employed the well-studied ChoK $\alpha$ inhibitor MN58b as a positive control [17, 19, 49] and evaluated the effects of MN58b therapy in tumor-bearing mice with NIRF imaging and MRS. The parallel use of two imaging techniques indicated a more complete story: MN58b bound to tumor ChoK $\alpha$ (blocking JAS239 accumulation) thus

attenuating flux through the Kennedy pathway (lowering tCho signals). It is important to note that the $25+30 \%$ reduction in tCho measured by in vivo MRS was mirrored by the $25+8 \%$ reduction in JAS239 accumulation, but NIRF measurements were less variable between animals resulting in greater statistical confidence. Moreover, optical imaging was easier to perform. While MRS required $1 \mathrm{~h}$ per mouse - including set-up, anesthesia, shimming, and scanning — the optical imaging technique could be performed on up to 5 mice simultaneously and required a simpler procedure involving one i.v. injection and follow-up surgery $24 \mathrm{~h}$ later.

To explore the therapeutic properties of JAS239, its ability to inhibit tumor growth and attenuate tCho in murine breast xenografts was determined. In orthotopic breast tumors, JAS239 significantly reduced tumor growth rate to the same degree as MN58b. MN58b at $4 \mathrm{mg} / \mathrm{kg}$ had previously been reported to lower PC levels in MDA-MB-231 tumor xenografts [22]. No observable or measurable toxicity was found using $4 \mathrm{mg} / \mathrm{kg}$ JAS239, and $2 \mathrm{mg} / \mathrm{kg}$ MN58b appeared tolerable but post-mortem toxicological studies revealed evidence of elevated blood urea nitrogen indicative of impaired renal function in these mice. Prior reports indicated MN58b to be tolerable when dosed daily for 5 days at $5 \mathrm{mg} / \mathrm{kg}$, but lethal at $10 \mathrm{mg} / \mathrm{kg}$
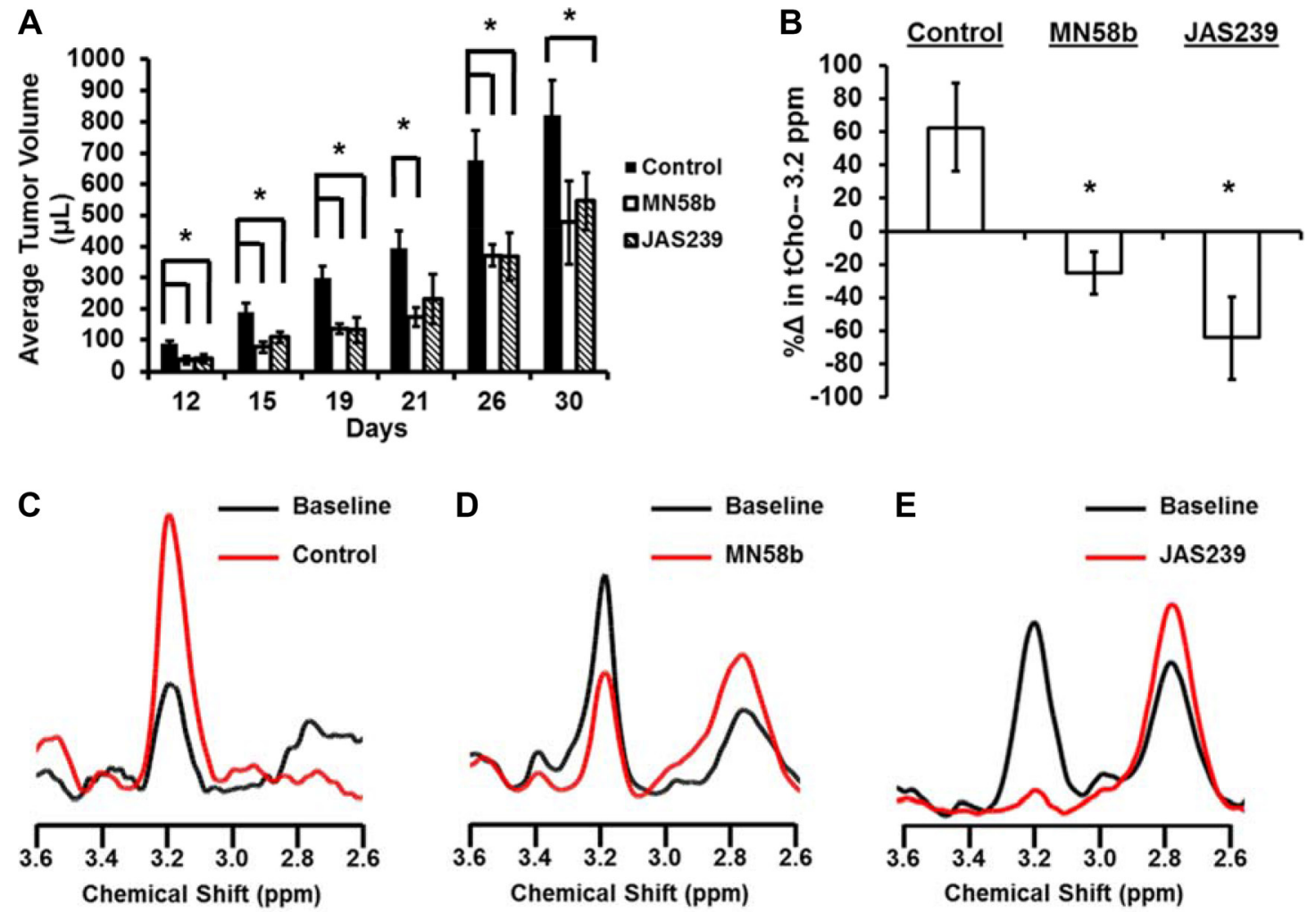

Figure 4: JAS239 exhibits ChoKa inhibition and slows breast tumor growth. (A) Treatment for 5 consecutive days with $2 \mathrm{mg} / \mathrm{kg}$ of MN58b $(n=4)$ or $4 \mathrm{mg} / \mathrm{kg}$ of JAS239 $(n=5)$ significantly reduced the growth rate of orthotopically-implanted 4175-Luc+ tumors, compared to control animals $(n=4)$. (B-E) The change in tCho $(3.2 \mathrm{ppm})$ within MDA-MB-231 tumors was measured using MRS (B) to show progressive tCho increase during saline treatment $(n=5)(\mathrm{B}, \mathrm{C})$, whereas reductions in tCho in response to 5 days of $2 \mathrm{mg} / \mathrm{kg} \mathrm{MN} 58 \mathrm{~b}$ $(n=4)(\mathrm{B}, \mathrm{D})$ or $4 \mathrm{mg} / \mathrm{kg} \mathrm{JAS} 239(n=3)(\mathrm{B}, \mathrm{E})$ were observed. Values are reported as $\pm \mathrm{SEM}$, *indicates $P<0.05$ compared to the control group. 
[49]. An optimized bis-pyridinium ChoK $\alpha$ inhibitor was recently shown effective at $10 \mathrm{mg} / \mathrm{kg}$ daily for 3 days, and body weight measurements indicated no adverse toxicities [50]. Both JAS239 and MN58b were capable of significantly reducing intratumoral tCho and increasing PUFA resonances associated with apoptosis [23, 45]. However, JAS239 was more effective at reducing tumor tCho, decreasing the levels down to baseline noise. In control tumors, rising tCho measured by in vivo MRS was an indicator of tumor growth during the week between pre- and post-therapy. Tumor status was also evaluated by histological methods. Both ChoK inhibitors effectively reduced cell number, reducing the proliferation marker Ki67 and inducing widespread cell death via apoptosis.

Expanding interest in ChoK $\alpha$ inhibitors for cancer therapy has raised the need for rapid and reliable methods to validate these therapies in vivo [5]. There have been concerns with the reliability of RECIST measurement as a marker of treatment responsiveness [51]. An addendum to the first clinical trial of TCD-717 included MRS evaluation of tCho levels as a supplemental treatment response indicator (Clinical Trials identifier: NCT01215864). MRS is the current gold standard for choline measurement in vivo due to its specificity, non-invasive acquisition, and feasible inclusion following MRI for RECIST measurements. To understand the degree to which choline metabolites represent a real biomarker of tumor progression and response to therapy, it is crucial to develop methods of identifying the oncogenes that contribute to heightened choline in cancerous tissue. ChoK $\alpha$ has been reported throughout the literature as a key contributor to aberrant choline metabolism [52], and its regulative role in cell growth and division directly links the Kennedy pathway to cancer malignancy. The use of NIRF choline mimetics to determine ChoK $\alpha$ status in whole tumors will provide a measure of histological tumor grade, a potential indicator of tumor margins during surgical resection, and a validation method for evaluating ChoK $\alpha$ inhibitors in the clinic.
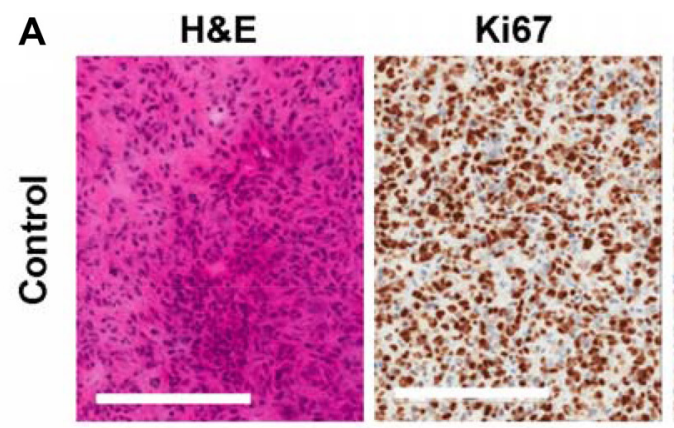

Casp-3
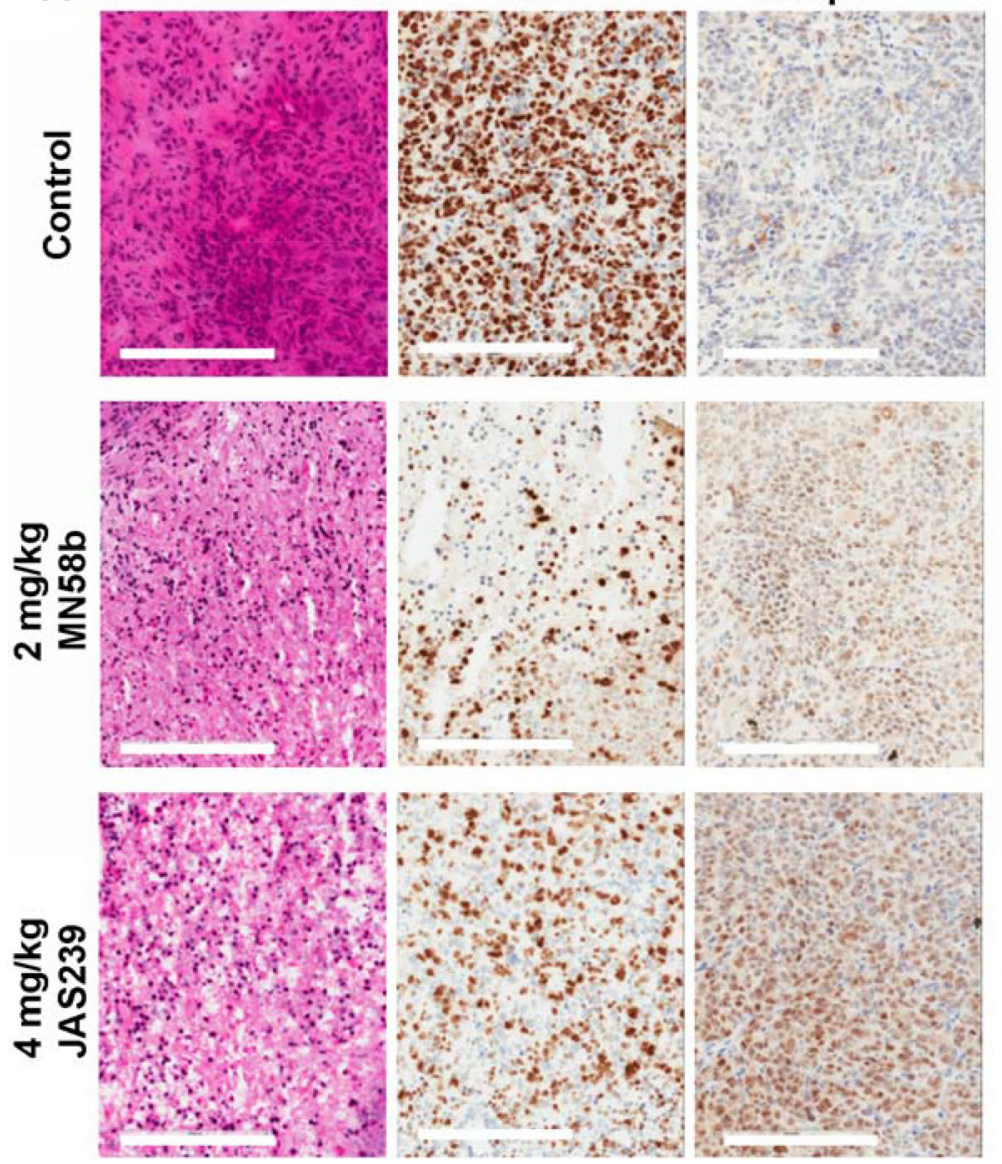
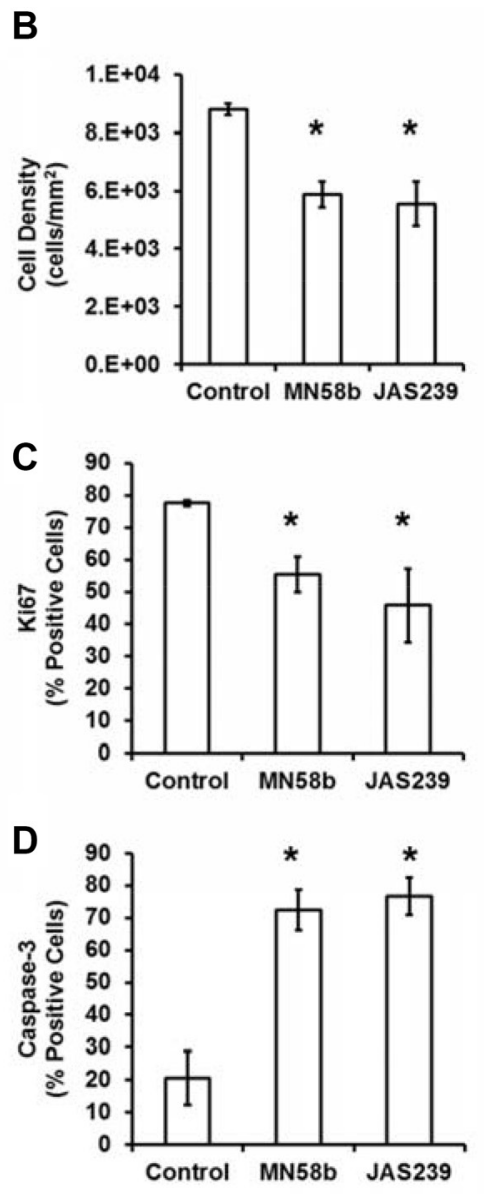

Figure 5: Histological assessment of tumors reveals reduced cell density, lower proliferation, and elevated apoptosis in response to ChoKa inhibitors. (A) H\&E staining (left column) of MDA-MB-231 tumor xenografts reveals lower cell density in MN58b (middle row) and JAS239 (bottom row) treated tumors compared to vehicle-treated tumors (top row). Reduced Ki67-positive nuclei (middle column) and heightened caspase-3 positive cells (right column) were also found in MN58b and JAS239 treated tumors. Significant (B) reduction in cell density, (C) lower Ki67 positivity, and (D) elevated caspase-3 were observed in both MN58b and JAS239 treated tumors relative to control, indicating apoptosis in response to ChoK inhibition. Scale bars represent $200 \mu \mathrm{m}$. Values are reported as \pm SEM and $n=3$ for each treatment cohort. *indicates $P<0.05$. 


\section{MATERIALS AND METHODS}

Cell lines: MDA-MB-231 human breast cancer cells were obtained from the ATCC and authorized via COI assay, STR analysis, and BacT/ALERT 3D. The 4175Luc + cell line, transfected to express luciferase and green fluorescent protein and derived from a MDA-MB-231 lung metastasis [44], was acquired from Dr. Andy Minn and maintained in $5 \mu \mathrm{g} / \mathrm{mL}$ blasticidin (Invitrogen), which was not included during experiments. Both cell lines were maintained in DMEM (Mediatech). MCF7 breast cancer cells (Chk-4 clone, MCF7 CK+) or the empty vector (MCF7 EV) were provided by Drs. Zaver Bhujwalla and Tariq Shah [43] and cultured in MEM (Mediatech) supplemented with $400 \mathrm{mg} / \mathrm{mL}$ G418 sulfate (Mediatech) that was not included during experiments. All cells were supplemented with 10\% FBS (HyClone Laboratories), $1 \%$ penicillin/streptomycin (Mediatech), and 1\% L-glutamine (Mediatech), and kept in a $37^{\circ} \mathrm{C}$ humidified atmosphere $\left(5 \% \mathrm{CO}_{2}\right)$. Cell lines were tested bi-monthly for mycoplasma. Cells were frozen in liquid nitrogen and used only at low passage numbers. Each cell line was characterized for ChoK $\alpha$ expression by Western blot [4].

\section{Cell viability assays}

MCF7 cells were plated for Trypan exclusion assays at $1.0 \times 10^{6}$ cells/well in 6-well plates and treated with MN58b or JAS239, synthesized in house [4]. At $17 \mathrm{~h}$, cells were collected by trypsinization, stained with Trypan Blue, and counted using a Neubauer hemocytometer. For 3-(4,5-Dimethylthiazol-2-yl)-2,5-diphenyltetrazolium bromide (MTT) assays, cells in 96-well plates $\left(7.5 \times 10^{4}\right.$ cells/well) were treated with JAS239 or MN58b overnight, and stained with $20 \mu \mathrm{L}$ of $5 \mathrm{mg} / \mathrm{mL}$ MTT (Sigma-Aldrich) for $2 \mathrm{~h}$, lysed with DMSO and scanned for absorbance using a SpectraMax M5 plate reader (Molecular Devices) at $550 \mathrm{~nm}$, subtracting background absorbance at $690 \mathrm{~nm}$ from each sample.

\section{Chok $\alpha$ activity assay}

Cells in 6-well plates $\left(1.0 \times 10^{6}\right.$ cells/well $)$ were incubated for $24 \mathrm{~h}$ then treated with JAS239 or MN58b. After $1 \mathrm{~h}$, cells were spiked for $1 \mathrm{~h}$ with $0.5 \mu \mathrm{Ci} / \mathrm{mL}$ $\left[\right.$ methyl- $\left.{ }^{14} \mathrm{C}\right]$-choline (PerkinElmer) and fixed with trichloroacetic acid. Aqueous cellular extracts were separated by thin layer chromatography (TLC) and the ${ }^{14} \mathrm{C}$ PC production measured by autoradiography on a Fujifilm FLA-7000 using previously described methods [4, 23].

\section{Confocal microscopy}

MDA-MB-231 cells plated on sterile glass coverslips were fixed in $4 \%$ paraformaldehyde, permeabilized in $0.2 \%$ Triton $\mathrm{X}-100$, and blocked in $1 \%$
BSA. Staining with 0 or $200 \mu \mathrm{M}$ JAS239 was performed $30 \mathrm{~min}$ prior or $1 \mathrm{~h}$ after application of rabbit anti-human ChoK $\alpha$ antibody (ab38290; Abcam, 1:1000 dilution). Coverslips were then stained with goat anti-rabbit antibody conjugated to Texas Red (Vector Laboratories; TI-1000, 1:500), dehydrated, and mounted with VectaShield (Vector Laboratories). Confocal micrographs were acquired on a Zeiss LSM 510META NLC using excitation (Ex.) $543 \mathrm{~nm}$ and emission (Em.) 565-615 $\mathrm{nm}$ for Texas Red and Ex. $633 \mathrm{~nm}$ and Em. $>650 \mathrm{~nm}$ for JAS239. The Coloc 2 FIJI software plug-in was used to assess colocalization of the anti-ChoK $\alpha$ antibody with JAS239 by calculating Pearson's Correlation Coefficients and Manders' Colocalization Coefficients for at least 3 separate ROIs [53].

\section{Animal model and tumor cell implantation}

All animal studies were approved by the Institutional Animal Care and Use Committee of the University of Pennsylvania. Six week old female athymic nude Foxn $1^{\text {nu/nu }}$ mice (National Cancer Institute) were housed in a temperature-controlled environment with $12 \mathrm{~h} \mathrm{light/dark}$ cycle. Anesthesia was induced using $2 \%$ isoflurane in oxygen for all experiments. For MCF7 tumors, mice were supplemented with 60 -day release $0.36 \mathrm{mg} 17 \beta$-estradiol tablets (Innovative Research of America) using a trochar in the nape of the neck. After 1 week, $4 \times 10^{6}$ cells in Matrigel (BD Biosciences) were inoculated into the left $(\mathrm{CK}+)$ and contralateral (EV) mammary fat pads. Subcutaneous xenografts, including those analyzed in MRI/MRS studies, were grown on the shoulder to allow for cloaking of the kidneys during optical imaging studies. Tumor growth was determined via caliper measurement of three orthogonal dimensions and volume calculated as length $*$ width $*$ height $* \pi / 6$.

\section{Optical imaging}

Bioluminescence and NIRF (Ex. $745 \mathrm{~nm}$; Em. $800 \mathrm{~nm}$ ) images were acquired in an IVIS Spectrum (PerkinElmer). NIRF is measured in Average Radiant Efficiency, photons per second $(\mathrm{p} / \mathrm{sec})$ corrected for the area of the region of interest (ROI) and the efficiency of the lamp $\left(\mu\right.$ Watt $* \mathrm{~cm}^{-2} /$ steradian $\left.^{-1}\right)$. For bioluminescence imaging, mice were injected i.p. with $150 \mathrm{mg} / \mathrm{kg}$ of firefly $D$-luciferin (Biosynth). Bioluminescent Radiance (p/sec/ $\mathrm{cm}^{2} / \mathrm{sr}$ ) was monitored by time-course imaging until the luminescence intensity plateaued. For NIRF imaging, mice were injected i.v. with $100 \mu \mathrm{L}$ vehicle or JAS239 (20 nmol). Two vehicle formulations were tested in mice bearing $4175-\mathrm{Luc}+$ tumors: the first was $0.1 \%$ Tween- 80 / $50 \mathrm{mM}$ Tris- $\mathrm{HCl}$, and the second was $1 \%$ ethanol diluted in $0.9 \%$ saline. ROIs with a $20 \%$ threshold were created from the bioluminescence image using the LivingImage software (PerkinElmer) program, and this region was used 
to analyze intratumoral JAS239 accumulation in the NIRF images. Resected organs were placed in 24-well plates and NIRF was measured to quantify JAS239 biodistribution. For diagnostic studies, mice bearing both MCF7-EV and MCF7-CK + tumors of approximately $200 \mu \mathrm{L}$ were injected with 20 nmol JAS239 in Tween-80/Tris ( 8 mice) or in ethanol/saline ( 7 mice). The cohorts were euthanized after $90 \mathrm{~min} / 24 \mathrm{~h}$ respectively, and tumor-bearing flanks were surgically exposed. NIRF from the tumor-bearing fat pads was subtracted from background muscle signal and the Average Radiant Efficiency measured.

\section{In vivo MRI}

\section{Animal preparation}

A mouse was anesthetized and secured to a custombuilt restraining device to minimize motion artifacts and the head positioned within a nose cone delivering isoflurane. A respiration pillow was placed dorsally to monitor respiration rate, and a thermister was inserted rectally to measure body temperature. Both sensors were connected to a small animal monitoring device (SA Instruments). The tumor was placed into a slotted-tube resonator (inner diameter $=11 \mathrm{~mm}$, depth $=9 \mathrm{~mm}$ ) built in-house and the probe was centered in the magnet. Body temperature was regulated at $37 \pm 1^{\circ} \mathrm{C}$ by blowing warm air into the magnet via a thermostatically controlled device (SA Instruments).

\section{In vivo single voxel spectroscopy}

Mice bearing subcutaneous 4175-Luc+ or MBMDA-231 tumors $(\sim 300 \mu \mathrm{L})$ underwent pre-treatment MRS scans in a $9.4 \mathrm{~T}$ horizontal bore magnet equipped with $40 \mathrm{G} / \mathrm{cm}$ gradients interfaced to an Agilent DirectDrive console (Agilent) operating vnmrj 2.3.C software. Multi-slice gradient and spin echo images were used for tumor localization. $T_{2}$-weighted spin echo anatomical images were acquired using a spin echo multi-slice (SEMS) pulse sequence $(\mathrm{TR}=1000 \mathrm{~ms}, \mathrm{TE}=10 \mathrm{~ms}$, number of slices $=20$, field of view $=20 \times 20 \mathrm{~mm}^{2}$, slice thickness $=1 \mathrm{~mm}, \mathrm{NT}=1$, matrix size $=256 \times 128$ ) and used for voxel selection. A single voxel ${ }^{1} \mathrm{H}$ PRESS spectrum was acquired in a $3 \times 3 \times 3 \mathrm{~mm}^{3}$ voxel $(\mathrm{TR}=3000$ $\mathrm{ms}, \mathrm{TE}_{1}=12.68 \mathrm{~ms}$ and $\mathrm{TE}_{2}=10.01 \mathrm{~ms}$, number of averages $=128$, complex points $=4096$, spectral width $=4000 \mathrm{~Hz}$ and acquisition time of $6 \mathrm{~min} 24 \mathrm{sec}$ ). Water suppression was achieved using the VAPOR sequence [54]. An unsuppressed water spectrum was acquired ( 8 averages) as a chemical shift and concentration reference. One week following initiation of treatment, ${ }^{1} \mathrm{H}$ MR spectra were acquired again. Spectra were processed using Mnova Lite 5.2.5 software (Mestrelab Research). Free induction decays were processed by $10 \mathrm{~Hz}$ apodization followed by Fourier transformation. Spectra were phased and chemical shift and baseline correction performed prior to fitting of the water $(4.7 \mathrm{ppm})$, tCho (3.2 ppm), PUFA (2.8 ppm), and lipid (1.3 ppm) resonances. The metabolite/water ratio was determined and the percent change was determined as [post-treatment ratio - pretreatment ratio] $* 100 \% /$ pre-treatment ratio.

\section{Animal treatments}

\section{Companion diagnostic study}

In vivo MRS was used to establish baseline tCho levels in a cohort of 10 mice bearing 4175-Luc+ tumors. Mice were injected i.p. for 5 consecutive days with either $100 \mu \mathrm{L}$ saline or $2 \mathrm{mg} / \mathrm{kg}$ MN58b. A follow-up MR scan was acquired 1 week after treatment. After the final MRS, each animal was injected i.v. with a trace dose $(20 \mathrm{nmol})$ of JAS239 in ethanol/saline. After $24 \mathrm{~h}$, the mice were euthanized and each tumor was analyzed for NIRF as described above.

\section{Tumor growth inhibition}

A cohort of 15 mice was inoculated with 4175Luc + tumors. Beginning 3 days post-inoculation, animals received a $100-\mu \mathrm{L}$ i.p. injection of either control DMSO/ saline, $2 \mathrm{mg} / \mathrm{kg} \mathrm{MN58b}$ or $4 \mathrm{mg} / \mathrm{kg} \mathrm{JAS} 239$ in DMSO/ saline daily for 5 days. Tumor volumes were assessed by caliper measurement.

\section{Pharmacodynamic indicators of Chok $\alpha$ inhibition}

A cohort of 15 mice was inoculated with MDAMB-231 cells. When a volume of $300 \mu \mathrm{L}$ was reached, tumors were scanned using MRS. Tumor volumes were measured using $T_{2}$-weighted images. The animals were separated into treatment groups, and for 5 consecutive days each group was injected i.p. with $100 \mu \mathrm{L}$ of DMSO/ saline vehicle $(n=5), 2 \mathrm{mg} / \mathrm{kg} \operatorname{MN} 58 \mathrm{~b}(n=4)$, or $4 \mathrm{mg} / \mathrm{kg}$ JAS239 $(n=3)$. Initial cohort sizes were 5 per condition, but some animals had to be removed from the study because the treatment was so effective that we were unable to place voxels within post-treatment tumors that were too small. Follow-up MRI/MRS scanning was performed on day 7 to assess tumor growth inhibition and changes in metabolite levels. After imaging, blood was collected into heparin-coated tubes by cardiac puncture. Resected tumors were embedded in Optimum Cryo-Temperature (Sakura Finetek), flash-frozen in liquid nitrogen, and stored at $-80^{\circ} \mathrm{C}$. Blood samples were submitted to the Ryan Veterinary Clinic Diagnostic labs for toxicology.

\section{Histopathology}

Hematoxylin and eosin staining and immunohistochemistry was performed as described previously [23]. Caspase-3 (R\&D Systems AF835) and Ki67 (Abcam ab16667) antibody staining was performed on a Bond Max automated staining system (Leica Microsystems) using the Bond Intense $\mathrm{R}$ staining kit (Leica Microsystems DS9263). An Aperio Scan Scope 
OS (Aperio Technology) was used to scan slides, and the Image Scope nuclear staining algorithm (version 9; Aperio Technology) was used to quantify $\mathrm{Ki} 67$ and caspase-3 positive nuclei in representative regions of each slide.

\section{Statistical analysis}

Statistical analyses of treated versus control values were performed in Microsoft Excel 2010 (Version 14.0.7128.5000 32-bit) using an unpaired Student's $t$-test unless noted otherwise. A $P$-value of $\leq 0.05$ was considered to be statistically significant. All error bars represent mean $\pm \mathrm{SEM}$.

\section{ACKNOWLEDGMENTS}

4175-Luc + cells were generously provided by Joan Massagué (Memorial Sloan Kettering Cancer Center) and Andy Minn of the Abramson Family Cancer Research Center. MCF7 cell lines were provided by Zaver Bhujwalla and Tariq Shah at Johns Hopkins University. Western blot assistance was provided by Mansi Shinde of the Department of Pharmacology. The immunohistochemical procedure was developed with input from Alex Glavis-Bloom of the Department of Cancer Biology. Confocal microscopy was performed in the Cell and Developmental Biology microscopy core with assistance from Jasmine Zhao and Angela Stout. Edward Chen of the Department of Pharmacology assisted with tumor model development. Imaging was performed in the Small Animal Imaging Facility with help from Julie Czupryna. The Pathology Core Laboratories of The Children's Hospital of Pennsylvania provided histopathology services. The PennVet diagnostic lab provided toxicology services. This work was supported by NIH R01-CA129176, T32-GM8076, F31-CA180328, and DoD Breast Cancer Concept Award BC076631.

\section{CONFLICTS OF INTEREST}

The authors declare no competing financial interests.

\section{Authors' contributions}

S.P.A., A.V.P., H.P., and E.J.D. designed research; S.P.A. and M.K. performed research; S.P.A. and A.V.P. performed synthesis of JAS239 and MN58b; S.P.A. and M.K. analyzed data; S.P.A. wrote manuscript with input from M.K., A.V.P., H.P., and E.J.D.

\section{REFERENCES}

1. Rodríguez-González A, de Molina AR, Fernández F, Ramos MA, Núñez MDC, Campos J, Lacal JC. Inhibition of choline kinase as a specific cytotoxic strategy in oncogenetransformed cells. Oncogene. 2003; 22:8803-12.
2. Clem BF, Clem AL, Yalcin A, Goswami U, Arumugam S, Telang S, Trent JO, Chesney J. A novel small molecule antagonist of choline kinase- $\alpha$ that simultaneously suppresses MAPK and PI3K/AKT signaling. Oncogene. 2011; 30:3370-80.

3. Glunde K, Bhujwalla ZM, Ronen SM. Choline metabolism in malignant transformation. Nat Rev Cancer. 2011; 11:835-48.

4. Arlauckas SP, Popov AV, Delikatny EJ. Direct inhibition of choline kinase by a near-infrared fluorescent carbocyanine. Mol Cancer Ther. 2014; 13:2149-58.

5. Arlauckas SP, Popov AV, Delikatny EJ. Choline kinase alpha-Putting the ChoK-hold on tumor metabolism. Prog Lipid Res. 2016; 63:28-40.

6. Ramírez de Molina A, Gutierrez R, Ramos MA, Silva JM, Silva J. Increased choline kinase activity in human breast carcinomas: clinical evidence for a potential novel antitumor strategy. Oncogene. 2002; 21:4317-22.

7. Ramírez de Molina A, Rodríguez-González A, Gutiérrez R, Martínez-Piñeiro L, Sánchez J, Bonilla F, Rosell R, Lacal J. Overexpression of choline kinase is a frequent feature in human tumor-derived cell lines and in lung, prostate, and colorectal human cancers. Biochem Biophysical Res Commun. 2002; 296:580-3.

8. Gillies RJ, Barry JA, Ross BD. In vitro and in vivo $13 \mathrm{C}$ and ${ }^{31} \mathrm{P}$ NMR analyses of phosphocholine metabolism in rat glioma cells. Magn Reson Med. 1994; 32:310-8.

9. Hernando E, Sarmentero-Estrada J, Koppie T, BeldaIniesta C, Ramírez de Molina V, Cejas P, Ozu C, Le C, Sánchez JJ, González-Barón M, Koutcher J, CordónCardó $\mathrm{C}$, Bochner $\mathrm{BH}$, et al. A critical role for choline kinase-alpha in the aggressiveness of bladder carcinomas. Oncogene. 2009; 28:2425-35.

10. Penet MF, Shah T, Bharti S, Krishnamachary B, Artemov D, Mironchik Y, Wildes F, Maitra A, Bhujwalla ZM. Metabolic imaging of pancreatic ductal adenocarcinoma detects altered choline metabolism. Clin Cancer Res. 2015; 21:386-95.

11. Jiménez B, del Peso L, Montaner S, Esteve P, Lacal JC. Generation of phosphorylcholine as an essential event in the activation of Raf-1 and MAP-kinases in growth factors-induced mitogenic stimulation. J Cell Biochem. 1995; 57:141-9.

12. Negendank W. Studies of human tumors by MRS: a review. NMR Biomed. 1992; 5:303-24.

13. Aboagye EO, Bhujwalla ZM. Malignant transformation alters membrane choline phospholipid metabolism of human mammary epithelial cells. Cancer Res. 1999; 59:80-4.

14. Ronen SM, Jackson LE, Beloueche M, Leach MO. Magnetic resonance detects changes in phosphocholine associated with Ras activation and inhibition in NIH 3 T3 cells. Br J Cancer. 2001; 84:691-6.

15. Ramírez de Molina A, Penalva V, Lucas L, Lacal JC. Regulation of choline kinase activity by Ras proteins involves Ral-GDS and PI3K. Oncogene. 2002; 21:937-46. 
16. Ramírez de Molina A, Gallego-Ortega D, Sarmentero J, Báñez-Coronel M, Martín-Cantalejo Y, Lacal JC. Choline kinase is a novel oncogene that potentiates RhoA-induced carcinogenesis. Cancer Res. 2005; 65:5647-53.

17. Rodríguez-González A, Ramírez de Molina A, Fernández F, Lacal JC. Choline kinase inhibition induces the increase in ceramides resulting in a highly specific and selective cytotoxic antitumoral strategy as a potential mechanism of action. Oncogene. 2004; 23:8247-59.

18. Glunde K, Raman V, Mori N, Bhujwalla ZM. RNA interference-mediated choline kinase suppression in breast cancer cells induces differentiation and reduces proliferation. Cancer Res. 2005; 65:11034-43.

19. Sanchez-Lopez E, Zimmerman T, Gomez del Pulgar T, Moyer MP, Lacal Sanjuan JC, Cebrian A. Choline kinase inhibition induces exacerbated endoplasmic reticulum stress and triggers apoptosis via CHOP in cancer cells. Cell Death Dis. 2013; 4:e933.

20. Lacal JC, Campos JM. Preclinical characterization of RSM-932A, a novel anticancer drug targeting the human choline kinase alpha, an enzyme involved in increased lipid metabolism of cancer cells. Mol Cancer Ther. 2015; 14:31-9.

21. Falcon SC, Hudson CS, Huang Y, Mortimore M, Golec JM, Charlton PA, Weber P, Sundaram H. A non-catalytic role of choline kinase alpha is important in promoting cancer cell survival. Oncogenesis. 2013; 2:e38.

22. Al-Saffar NMS, Troy H, Ramírez de Molina A, Jackson LE, Madhu B, Griffiths JR, Leach MO, Workman P, Lacal JC, Judson IR, Chung Y. Noninvasive magnetic resonance spectroscopic pharmacodynamic markers of the choline kinase inhibitor MN58b in human carcinoma models. Cancer Res. 2006; 66:427-34.

23. Kumar M, Arlauckas SP, Saksena S, Verma G, Ittyerah R, Pickup S, Popov AV, Delikatny EJ, Poptani H. Magnetic resonance spectroscopy for detection of choline kinase inhibition in the treatment of brain tumors. Mol Cancer Ther. 2015; 14:899-908.

24. Delikatny EJ, Chawla S, Leung DJ, Poptani H. MR-visible lipids and the tumor microenvironment. NMR Biomed. 2011; 24:592-611.

25. Podo F, Canevari S, Canese R, Pisanu ME, Ricci A, Iorio E. MR evaluation of response to targeted treatment in cancer cells. NMR Biomed. 2011; 24:648-72.

26. Horská A, Barker PB. Imaging of brain tumors: MR spectroscopy and metabolic imaging. Neuroimaging Clin N Am. 2010; 20:293-310.

27. Lodi A, Ronen SM. Magnetic resonance spectroscopy detectable metabolomic fingerprint of response to antineoplastic treatment. PLoS ONE. 2011; 6:e26155.

28. Challapalli A, Sharma R, Hallett WA, Kozlowski K, Carroll L, Brickute D, Twyman F, Al-Nahhas A, Aboagye EO. Biodistribution and radiation dosimetry of deuterium-substituted ${ }^{18} \mathrm{~F}$-fluoromethyl- $\left[1,2-{ }^{2} \mathrm{H}^{4}\right]$ choline in healthy volunteers. J Nucl Med. 2014; 55:256-63.
29. Gomez MV, Domino EF, Sellinger OZ. Effect of hemicholinium-3 on choline distribution in vivo in the canine caudate nucleus. Biochem Pharmacol. 1970; 19:1753-60.

30. Hara T, Bansal A, DeGrado TR. Choline transporter as a novel target for molecular imaging of cancer. Mol Imaging. 2006; 5:498-509.

31. Boobis AR, Gibson A, Stevenson RW. Ethanol protection against hemicholinium toxicity in mice. Biochem Pharmacol. 1975; 24:485-8.

32. Miyake T, Parsons SJ. Functional interactions between Choline kinase $\alpha$, epidermal growth factor receptor and c-Src in breast cancer cell proliferation. Oncogene. 2012; 31:1431-41.

33. Mori N, Wildes F, Kakkad S, Jacob D, Solaiyappan M, Glunde K, Bhujwalla ZM. Choline kinase- $\alpha$ protein and phosphatidylcholine but not phosphocholine are required for breast cancer cell survival. NMR Biomed. 2015; 28:1697-706.

34. Jobsis FF. Noninvasive, infrared monitoring of cerebral and myocardial oxygen sufficiency and circulatory parameters. Science. 1977; 198:1264-7.

35. Weissleder R, Ntziachristos V. Shedding light onto live molecular targets. Nat Med. 2003; 9:123-8.

36. Mahmood U, Weissleder R. Near-infrared optical imaging of proteases in cancer. Mol Cancer Ther. 2003; 2:489-96.

37. van de Ven S. Optical imaging of the breast. Cancer Imaging. 2008; 8:206-15.

38. Durduran T, Choe R, Baker WB, Yodh AG. Diffuse optics for tissue monitoring and tomography. Rep Prog Phys. 2010; 73:076701.

39. van Dam GM, Themelis G, Crane LMA, Harlaar NJ, Pleijhuis RG, Kelder W, Sarantopoulos A, de Jong JS, Arts HJG, van der Zee AGJ, Bart J, Low PS, Ntziachristos V. Intraoperative tumor-specific fluorescence imaging in ovarian cancer by folate receptor- $\alpha$ targeting: first in-human results. Nat Med. 2011; 17:1315-9.

40. De Grand AM, Frangioni JV. An operational near-infrared fluorescence imaging system prototype for large animal surgery. Technol Cancer Res Treat. 2003; 2:553-62.

41. Crane LMA, Themelis G, Pleijhuis RG, Harlaar NJ, Sarantopoulos A, Arts HJG, van der Zee AGJ, Ntziachristos V, Vasilis N, van Dam GM. Intraoperative multispectral fluorescence imaging for the detection of the sentinel lymph node in cervical cancer: a novel concept. Mol Imaging Biol. 2011; 13:1043-9.

42. Judy RP, Keating JJ, DeJesus EM, Jiang JX, Okusanya OT, Nie S, Holt DE, Arlauckas SP, Low PS, Delikatny EJ, Singhal S. Quantification of tumor fluorescence during intraoperative optical cancer imaging. Sci Rep. 2015; 5:16208.

43. Shah T, Wildes F, Penet MF, Winnard PT, Glunde K, Artemov D, Ackerstaff E, Gimi B, Kakkad S, Raman V, Bhujwalla ZM. Choline kinase overexpression increases 
invasiveness and drug resistance of human breast cancer cells. NMR Biomed. 2010; 23:633-42.

44. Minn AJ, Gupta GP, Siegel PM, Bos PD, Shu W, Giri DD, Viale A, Olshen AB, Gerald WL, Massagué J. Genes that mediate breast cancer metastasis to lung. Nature. 2005; 436:518-24.

45. Hakumäki JM, Poptani H, Sandmair AM, Ylä-Herttuala S, Kauppinen RA. ${ }^{1} \mathrm{H}$ MRS detects polyunsaturated fatty acid accumulation during gene therapy of glioma: implications for the in vivo detection of apoptosis. Nat Med. 1999; 5:1323-7.

46. Campos J, del Carmen Núñez M, Rodríguez V, Entrena A, Hernández-Alcoceba R, Fernández F, Lacal JC, Gallo MA, Espinosa A. LUMO energy of model compounds of bispyridinium compounds as an index for the inhibition of choline kinase. Eur J Med Chem. 2001; 36:215-25.

47. Sánchez-Martín R, Campos JM, Conejo-García A, CruzLópez O, Báñez-Coronel M, Rodríguez-González A, Gallo MA, Lacal JC, Espinosa A. Symmetrical bisquinolinium compounds: new human choline kinase inhibitors with antiproliferative activity against the HT-29 cell line. J Med Chem. 2005; 48:3354-63.

48. Brophy PJ, Vance DE. Copurification of choline kinase and ethanolamine kinase from rat liver by affinity chromatography. FEBS Lett. 1976; 62:123-5.
49. Hernández-Alcoceba R, Fernández F, Lacal JC. In vivo antitumor activity of choline kinase inhibitors: a novel target for anticancer drug discovery. Cancer Res. 1999; 59:3112-8.

50. Trousil S, Kaliszczak M, Schug Z, Nguyen QD, Tomasi G, Favicchio R, Brickute D, Fortt R, Twyman FJ, Carroll L, Kalusa A, Navaratnam N, Adejumo T, et al. The novel choline kinase inhibitor ICL-CCIC-0019 reprograms cellular metabolism and inhibits cancer cell growth. Oncotarget. 2016; 7:37103-20. doi: 10.18632/ oncotarget.9466.

51. Jaffe CC. Measures of response: RECIST, WHO, and new alternatives. J Clin Oncol. 2006; 24:3245-51.

52. Glunde K, Serkova NJ. Therapeutic targets and biomarkers identified in cancer choline phospholipid metabolism. Pharmacogenomics. 2006; 7:1109-23.

53. Dunn KW, Kamocka MM, McDonald JH. A practical guide to evaluating colocalization in biological microscopy. Am J Physiol Cell Physiol. 2011; 300:C723-42.

54. Tkac I, Starcuk Z, Choi IY, Gruetter R. In vivo ${ }^{1} \mathrm{H}$ NMR spectroscopy of rat brain at $1 \mathrm{~ms}$ echo time. Magn Reson Med. 1999; 41:649-56. 